Sādhanā Vol. 36, Part 2, April 2011, pp. 181-192. (C) Indian Academy of Sciences

\title{
Numerical simulation with finite element and artificial neural network of ball indentation for mechanical property estimation
}

\author{
KAMAL SHARMA*, VIVEK BHASIN, \\ $\mathrm{K}$ K VAZE and A K GHOSH \\ Reactor Safety Division, Bhabha Atomic Research Centre (BARC), Trombay, \\ Mumbai 400 085, India \\ e-mail: hello_kamal@yahoo.com
}

MS received 25 March 2010; revised 20 January 2011; accepted 25 February 2011

\begin{abstract}
A combined mechanical property evaluation methodology with ABI (Automated Ball Indentation) simulation and Artificial Neural Network (ANN) analysis is evolved to evaluate the mechanical properties for Carbon Manganese Steel (SA-333 Grade-6) and Stainless Steel (SS-304LN). The experimental load deflection data is converted into meaningful mechanical properties for these materials and their evaluated property is verified with experimental tensile specimen results. An ANN database is generated with the help of contact type finite element analysis by numerically simulating the ABI process for various magnitudes of yield strength $\left(\sigma_{y p}\right)$ (200 MPa-400 MPa) with a range of strain hardening exponent (n) (0.05-0.5) and strength coefficient $(\mathrm{K})(600 \mathrm{MPa}-1600 \mathrm{MPa})$. For the present problem, a ball indenter of $1.57 \mathrm{~mm}$ diameter having Young's modulus higher than test piece is used to minimize the error due to indenter deformation. Test piece dimension is kept large enough in comparison to the indenter configuration in the simulation to minimize the deflection at the outer edge of the test piece. Further, this database after the neural network training; is used to analyse measured material properties of different test pieces. The ANN predictions are reconfirmed with contact type finite element analysis for an arbitrary selected test sample. The methodology evolved in this work can be extended to predict material properties for any irradiated nuclear material in the service. Extensions of the ABI tests and the associated database analysis could lead to evaluation of the indentation energy to fracture needed for the structural integrity assessment of aged components.
\end{abstract}

Keywords. Automated ball indentation; ANN; finite element simulation; irradiated nuclear material; miniature specimen testing.

*For correspondence 


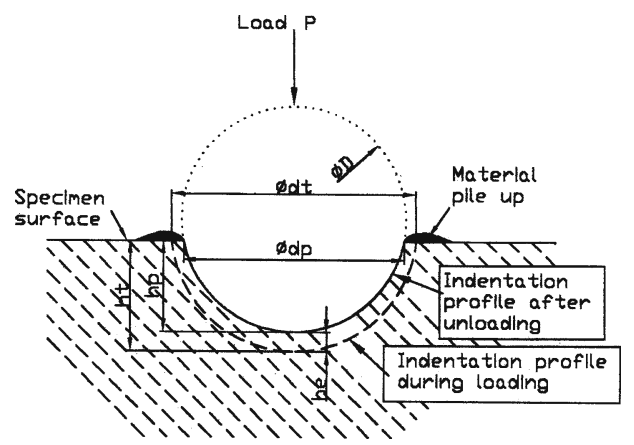

Nomenclature:

$\mathrm{d}_{\mathrm{t}}$ is the total indentation diameter.

$\mathrm{h}_{\mathrm{t}}$ is total depth of indentation.

$\mathrm{d}_{\mathrm{p}}$ is the diameter of plastic indentation.

$\mathrm{h}_{\mathrm{p}}$ is depth after unloading.

$h_{e}$ is the elastic component of deformation.

$\mathrm{D}$ is the ball diameter.

$\mathrm{P}$ is the applied load.

Figure 1. Illustration of parameters of ball indentation.

\section{Introduction}

Nuclear reactor components and power piping are generally subjected to various forms of thermal cycling. As a result, the mechanical properties of the materials of the components get degraded. It is therefore of prime importance, that the altered mechanical properties of the degraded materials be known for life assessment of the components of the nuclear and thermal power plants. So determination of mechanical properties of materials by using non-conventional techniques has been an active area of research for a long time. Among some non-destructive methods for determining mechanical properties of materials, a semi-destructive type of testing, called 'Automated ball indentation' (ABI) has been developed. Figure 1 is a schematic representation of the indentation profile in an $\mathrm{ABI}$ test. It is one of the most promising techniques to evaluate mechanical properties of materials, as it requires small size of test materials. For the validity of this material property evaluation procedure with $\mathrm{ABI}$, the tests reported here have been initially carried out for standard materials with known mechanical properties.

The 'automated ball indentation' technique is capable of extracting degraded mechanical behaviour and properties of thermally aged or irradiated materials from very small specimens. The objective of miniaturized specimen testing technology is to enable the characterization of mechanical behaviour while using a greatly reduced minimum volume of material. In most of the cases extracting specimen from components, for conducting conventional tests for evaluation of properties of the material, is neither possible nor permissible. The significance of this technology is obvious to the nuclear industry where neutron irradiation space is limited and irradiation cost scales up with specimen volume. In addition, the substantial advantages resulting from the application of this technology in non-nuclear industries are now beginning to be realized.

For this evaluation the specimen undergoes multiple indentations by a spherical ball indenter. Furthermore, this method can be used to characterize weldments and associated heat affected zone (HAZ), it also avoids the need to fabricate test specimen, and it is relatively rapid.

\section{Review of earlier work}

A few research groups have published a series of investigations on ball indentation technique to evaluate mechanical properties. For evaluating mechanical properties many theories and models have been developed and some of the mechanical properties such as yield strength, ultimate tensile strength, strength coefficient, true stress-true strain curves and strain hardening coefficient are evaluated with these theories. It was Mayer (1908) who first developed a relationship 
between the mean pressure and indentation diameter to evaluate the yield strength of materials. Tabor (1951) gave an empirical relationship to find the representative strain of materials while indentation is done through a hard spherical ball. However, Tabor's relation holds very close to the test observation when the indentation process becomes fully plastic.

Haggag (1993) did extensive work and developed an automated ball indentation test set-up for determining flow properties directly from the test around a small volume of material. They developed a field indentation microprobe to evaluate the integrity of metallic structure nondestructively. They used various base materials and found excellent agreement with standard ASTM uni-axial tensile and fracture toughness data. This group also applied the ABI technique to measure through the thickness variations of mechanical properties in the pressure vessels. The location dependence of the mechanical properties was successfully measured by Murthy et al (1999). Gradients in mechanical and fracture properties of SA 533B steel welds were studied using ball indentation technique. The local stress-strain behaviours of different microstructure zones of the weld were observed at different temperatures.

Haggag \& Nansted (1989) also described a simple technique for estimating the fracture toughness by coupling the measured flow properties with a modified but empirically correlated critical fracture strain model. This technique predicted fracture toughness values that differed by less than $11 \%$ from measured values for both A 515 grade 70 carbon steel and A 533-grade B class 1 pressure vessel steels respectively. Some other groups also studied properties and fracture toughness properties of welds and their HAZ using different types of materials and found good agreement with ASTM standard. Mathew et al (1999) studied the effects of low temperature aging $(673 \mathrm{~K})$ up to 18 months on the mechanical and fracture properties of cast CF-8 stainless steel in the range of 173-423 K. These studies have been carried out using non-destructive ball indentation tests. Standard Charpy and tensile tests were also carried out to complement the ball indentation data. A theoretical model is proposed to estimate fracture toughness of ferritic steel in the transition region from ball indentation test data by Byuan et al (1998). The key concept of the model is that the indentation energy to a critical load is related to fracture energy of material.

\section{Ball indentation experimental procedure}

The set-up of ball indentation is shown in figure $2 \mathrm{a}$ and close-up view is shown in figure $2 \mathrm{~b}$. All the indentation tests have been conducted in a laboratory scale BI set-up. Standard table-top mechanical testing machine of $10 \mathrm{kN}$ capacity with a $5 \mathrm{kN}$ load cell has been converted to BI test set-up. A PC is attached to the machine to control the test and store the digital data for post test processing. Software on FORTRAN was developed for test control and data acquisition. The software has provision to input the diameter of the indentation ball fitted on the loading member. The displacement rate, extent of unloading, the number of cycles and the maximum total indentation depth measuring by LVDT are also provided as user input. LVDT used had resolution of 0.05 micrometer. The LVDT, clamped to the loading members, is placed on the specimen surface. Both the plastic depth (hp) and total depth $\left(h_{t}\right)$ are measured by the LVDT. Then the values of total indentation diameter $\left(\mathrm{d}_{\mathrm{t}}\right)$ and plastic indentation diameter $\left(\mathrm{d}_{\mathrm{p}}\right)$ are evaluated based on measured ht and hp respectively. Displacement rate/cross head speed is $1 \mathrm{~mm} / \mathrm{min}$. Software was written in FORTRAN to process the data for carrying out different calculations, as discussed in the methodology section. The indentation balls were made of tungsten carbide and were $1.57 \mathrm{~mm}$ in diameter on the material to be tested. These balls were brazed into spherical groove machined at the bottom of the loading arm. The test coupons employed were $20 \mathrm{~mm}$ in length, $20 \mathrm{~mm}$ in width and thickness was $14 \mathrm{~mm}$ and $18 \mathrm{~mm}$ for SS-304 LN and SA-333Gr6 respectively. These 

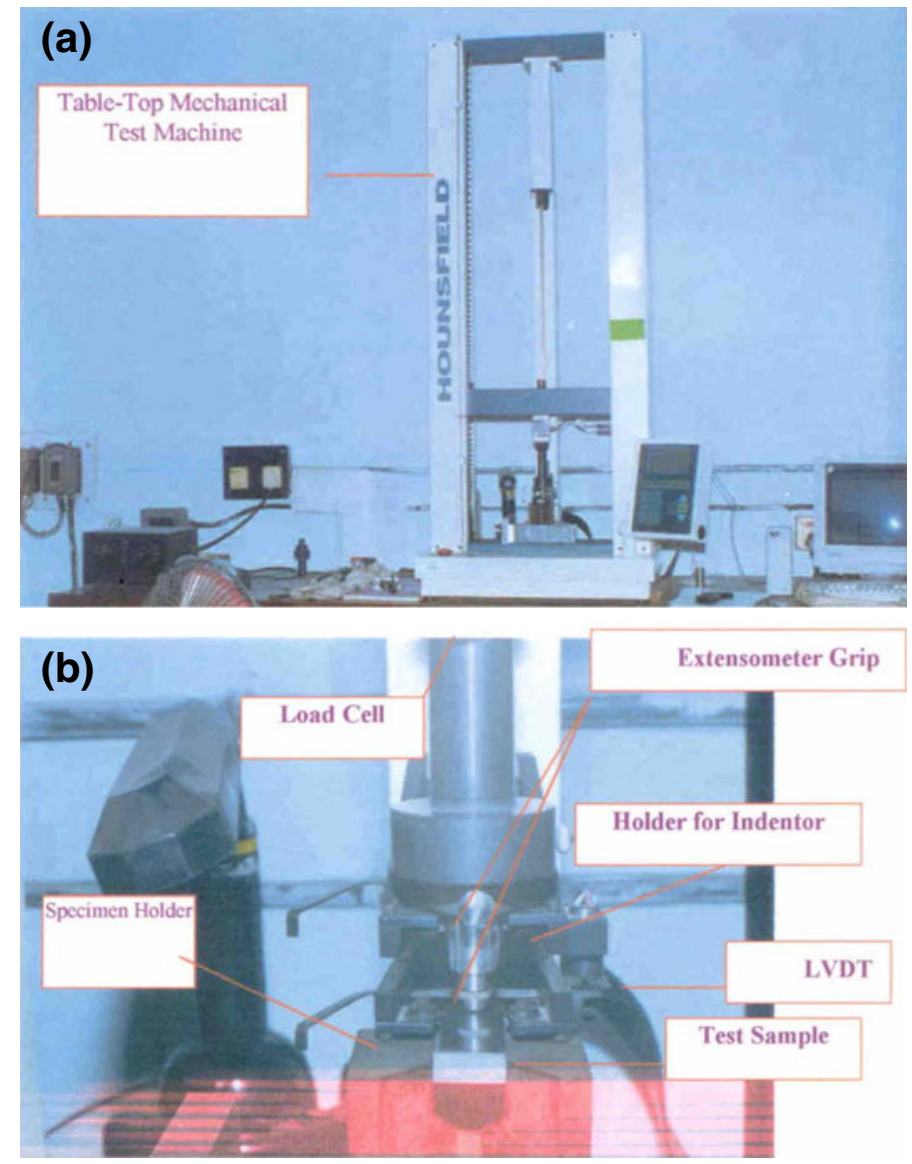

Figure 2. (a) Set-up for ball indention test. (b) Close-up view of BI Test set-up.

coupons were removed from extruded pipes/tubes. The surface of the BI test specimens was polished using 600 grit emery papers for neglecting the effect of roughness. A pair of spring loaded clamps holds the test specimen on the test bed. At the start of the test, the LVDT and the load cell readings initialized to zero through software. All the tests were terminated when the total indentation depth measured by LVDT is just less than the indenting ball radius. The ABI analyses are based primarily on elasticity and plasticity theories. At first, the surface of the test specimen is polished with a polishing tool. Figure 3 shows multiple cycles loading unloading for the material coupons and this shows that the load increases approximately linearly with penetration depth. The linear increase is the consequence of two nonlinear but opposing processes occurring simultaneously; the nonlinear increase in the applied load with penetration depth because of the spherical geometry of the indenter is offset by the power-law work hardening behaviour of the test material. For determining a full true stress-true plastic strain curve at this location, this cyclic loading can be continued; however the maximum total indentation depth $\left(\mathrm{h}_{\mathrm{t}}\right)$ should not exceed one half of diameter D of indenter. Finally, the useful mechanical properties like yield strength, ultimate tensile strength, strength and hardening coefficients and fracture toughness can be obtained from ABI technique. However in the present finite element simulation of the 


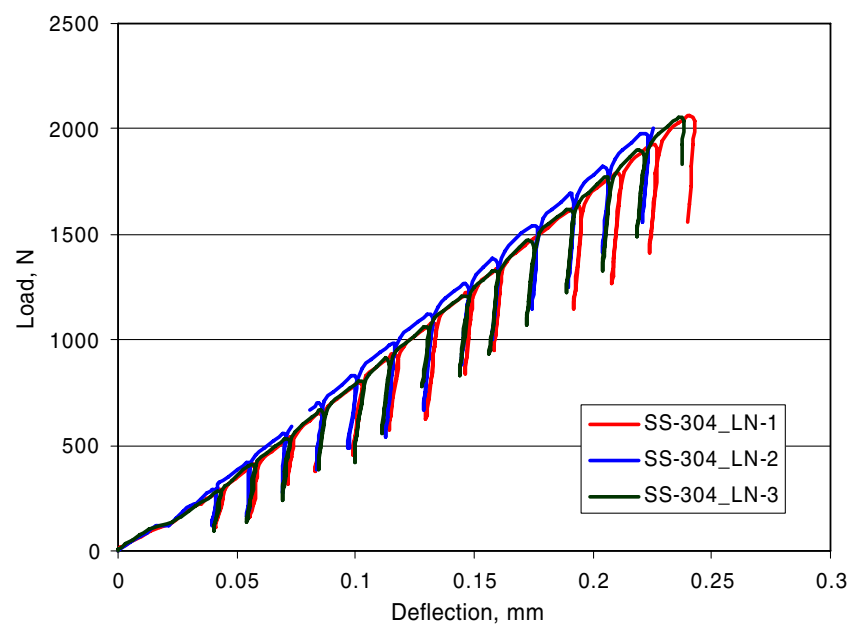

Figure 3. Load deflection curve for SS-304 LN material.

experimental set-up the unloading is not done and elastic spring back is calculated by the elastic modulus only (Appendix A).

\section{Numerical model and analysis procedure}

In the present work due to spherical nature of indenter and circular specimen fully axisymmetric 2D model is created. The finite element model of the ball indenter and specimen is shown in the figure 4 and the deformed model enlarged at contact area due to the loading is shown in figure 5. After validation plane 42 and contact 48 elements of ANSYS are chosen. For the present analysis, range of material property used which is given below. The indenter has been simulated Young's Modulus $645 \mathrm{MPa}$ is used to minimize the error due to indenter deformation. This helps in simulating the hardened ball stiffness. The indenter in this analysis has $1.57 \mathrm{~mm}$ diameter. The indenter and specimen have been modelled in two sections (areas) respectively. The lower section (area) of indenter and upper section of test specimen consist of contact 48 elements. The upper section of indenter and lower section of specimen consist of planer 42 elements. Indenter is defined as contactor surface and the specimen is defined as target surface for the contact pair. Large strain and large displacement option is applied for the analysis and constrained function contact algorithm is used for the solution. Very finer mesh has been generated at the contact element location and check the convergence.

\subsection{Material input data}

Material data for specimen:

$\sigma_{y p}=200$ to $400 \mathrm{MPa}$ with increment of $25 \mathrm{MPa} ; \boldsymbol{K}=600$ to $1650 \mathrm{MPa}$ with increment of $150 \mathrm{Mpa} ; \boldsymbol{n}=0.1$ to 0.5 with increment of 0.05 ; Ultimate limit $\left(\sigma_{\mathrm{uts}}\right)=700 \mathrm{MPa}$; Young's modulus $(\mathrm{E})=200 \mathrm{GPa} ; \boldsymbol{v}($ Poisson Ratio $)=0.3$.

Material data for stiff indenter:

Young's modulus $(\mathrm{E})=645 \mathrm{GPa}$ (Tungsten Carbide); $v$ (Poisson Ratio $)=0.26$; Diameter $=$ $1.57 \mathrm{~mm}$. 


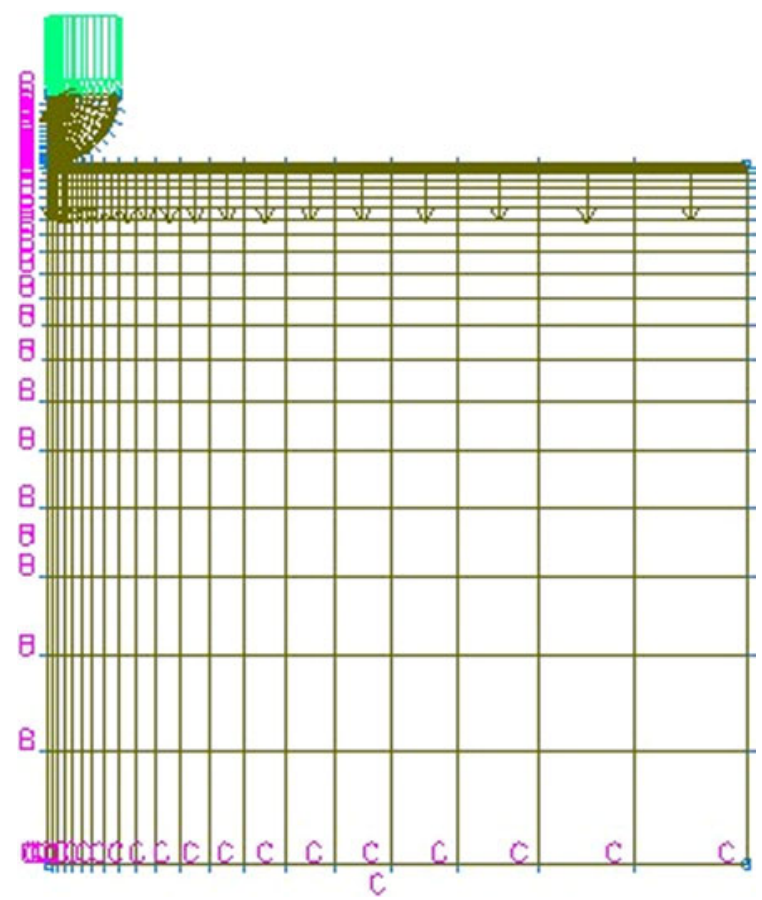

Figure 4. FE model of indenter and test specimen.

\subsection{Analysis}

Analysis of indenter and specimen finite element model has been carried out for different values of $\sigma_{y p}, \mathrm{~K}$ and $n$ and for each case the input material data is varied and load is incremented to simulate the indentation process. For the analysis purpose the power law is taken into consideration

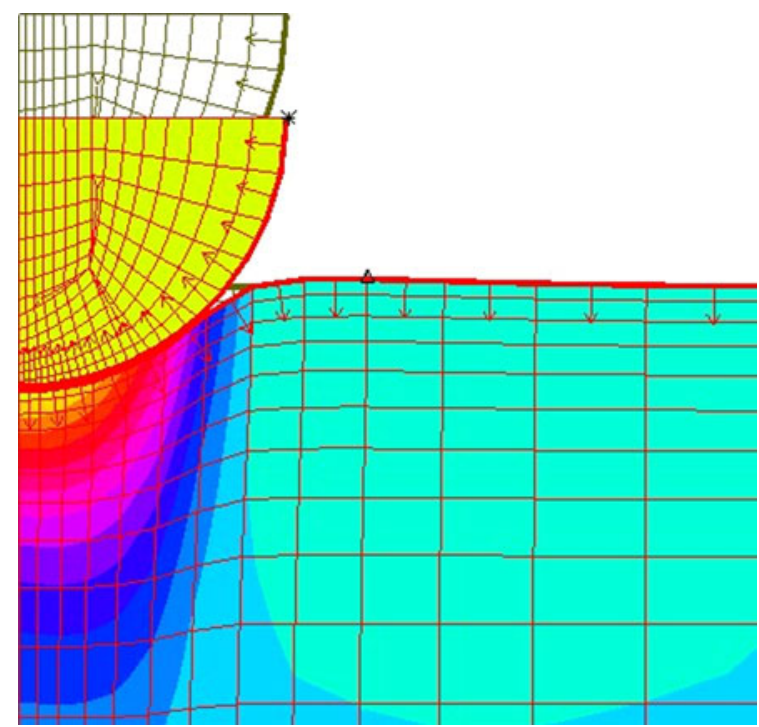

Figure 5. Deformed FE model enlarge at the contact. 
to generate the stress-strain data for the different combinations of $\sigma_{y p}, K$ and $n$ and the generated database is used as material property input for the analysis. The nonlinear analysis is carried out for the case with varying steps of pressure from $3 \mathrm{MPa}$ to $900 \mathrm{MPa}$. After each analysis load-deflection curves are obtained and data base is generated for the neural network tool box.

\section{Artificial neural network}

Artificial neural network is composed of simple elements operating in parallel. This is basically a network or interconnections of artificial neurons. These elements are inspired by biological nervous system. As in nature, the network function is determined largely by the connections between elements. We can train a neural network to perform a particular function by adjusting the values of the connections (weights) between elements. In the present work, the artificial neural network (ANN) is used for performing logical function on its input such as load-deflection. The load-deflection input is provided to the ANN for the range of $\mathrm{K}$, $\mathrm{n}$, and $\sigma_{y p}$ values. This data has been used to train the ANN. The neural network used in this case for the purpose of data inversion is an example of multi layer perceptron (MLP) network with back propagation algorithm. It consists of 6 layers before the output stage, 5 layers consisting of the intermediate neurons also known as hidden layers. The first layer is an input stage. The command TRAINLM

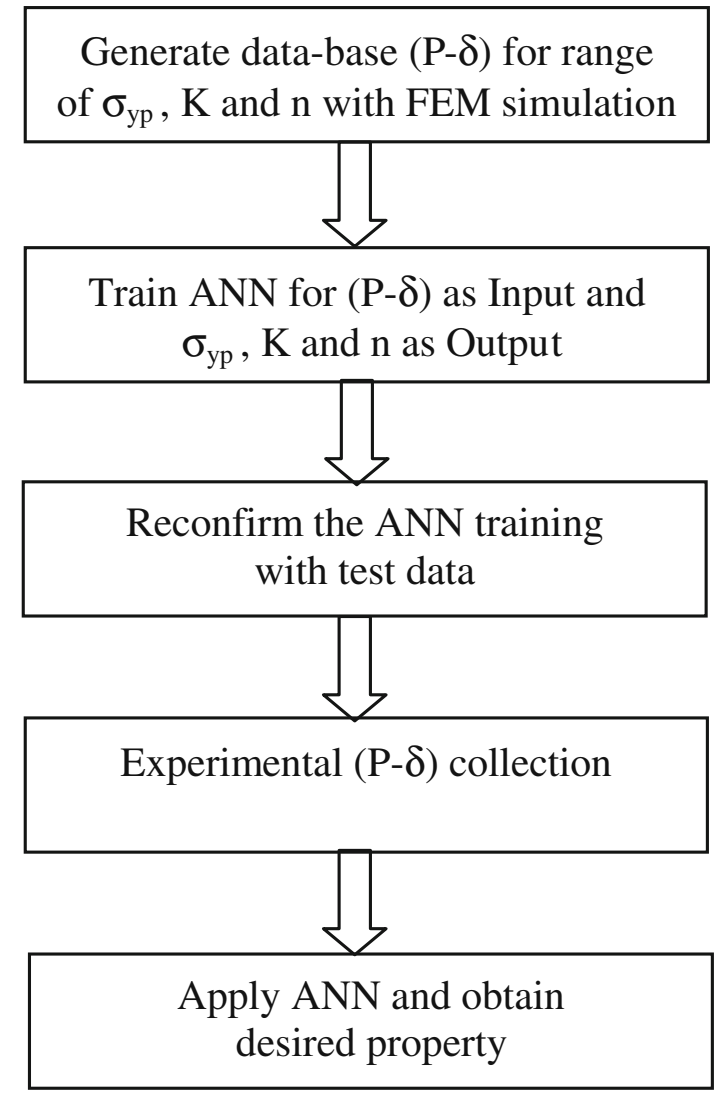

Figure 6. Methodology for the evaluation. 
Table 1. Comparison between simulated value and analyses value for $n=0.2$.

\begin{tabular}{|c|c|c|c|c|c|c|}
\hline \multicolumn{3}{|c|}{ Simulated value } & \multicolumn{2}{|c|}{ Analytical value } & \multirow[t]{2}{*}{$\%$ Error in $n$} & \multirow[t]{2}{*}{$\%$ Error in $K$} \\
\hline$N$ & $K(\mathrm{MPa})$ & $\sigma(\mathrm{MPa})$ & $n$ & $K(\mathrm{MPa})$ & & \\
\hline 0.2 & 600 & 240 & 0.197 & 587.5 & 1.5 & 2.08 \\
\hline 0.2 & 600 & 260 & 0.202 & 590.1 & 1.0 & 1.65 \\
\hline 0.2 & 800 & 280 & 0.203 & 790.2 & 1.5 & 1.225 \\
\hline 0.2 & 800 & 300 & 0.2047 & 790.3 & 2.35 & 1.21 \\
\hline 0.2 & 1000 & 300 & 0.198 & 1021.7 & 1.0 & 2.17 \\
\hline 0.2 & 1200 & 380 & 0.196 & 1179.4 & 2.0 & 1.71 \\
\hline 0.2 & 1400 & 400 & 0.195 & 1381.8 & 2.5 & 1.3 \\
\hline
\end{tabular}

Table 2. Comparison between simulated value and analyses value for $n=0.4$.

\begin{tabular}{|c|c|c|c|c|c|c|}
\hline \multicolumn{3}{|c|}{ Simulated value } & \multicolumn{2}{|c|}{ Analytical value } & \multirow[t]{2}{*}{$\%$ Error in $n$} & \multirow[t]{2}{*}{$\%$ Error in $K$} \\
\hline$N$ & $K(\mathrm{MPa})$ & $\sigma(\mathrm{MPa})$ & $n$ & $K(\mathrm{MPa})$ & & \\
\hline 0.4 & 600 & 220 & 0.383 & 602.3 & 4.25 & 0.38 \\
\hline 0.4 & 700 & 240 & 0.389 & 696.2 & 2.75 & 0.54 \\
\hline 0.4 & 800 & 260 & 0.408 & 791.3 & 2.0 & 1.08 \\
\hline 0.4 & 800 & 300 & 0.387 & 791.1 & 3.25 & 1.11 \\
\hline 0.4 & 1000 & 320 & 0.392 & 1016.2 & 2.0 & 1.62 \\
\hline 0.4 & 1000 & 340 & 0.389 & 1013.7 & 2.75 & 1.37 \\
\hline 0.4 & 1200 & 360 & 0.382 & 1211.6 & 4.5 & 0.96 \\
\hline 0.4 & 1500 & 380 & 0.391 & 1502.3 & 2.25 & 0.15 \\
\hline 0.4 & 1400 & 380 & 0.388 & 1404.8 & 3.0 & 0.34 \\
\hline 0.4 & 1500 & 400 & 0.389 & 1501.1 & 2.75 & 0.07 \\
\hline
\end{tabular}

Table 3. Comparison in the evaluated properties of material from empirical relation and finite element with ANN approach.

\begin{tabular}{|c|c|c|c|c|c|c|c|c|c|}
\hline \multirow[t]{2}{*}{$\begin{array}{l}\text { Sl. } \\
\text { No. }\end{array}$} & \multirow[t]{2}{*}{ Material } & \multicolumn{4}{|c|}{$\begin{array}{l}\text { Experimental data }+ \text { empirical } \\
\text { relation approach }\end{array}$} & \multicolumn{4}{|c|}{$\begin{array}{c}\text { Experimental data }+ \text { Finite element }+ \\
\text { ANN approach }\end{array}$} \\
\hline & & $\begin{array}{c}\mathrm{YS} \\
(\mathrm{MPa})\end{array}$ & $\begin{array}{l}\text { UTS } \\
(\mathrm{MPa})\end{array}$ & $\mathrm{n}$ & $\begin{array}{c}\mathrm{K} \\
(\mathrm{MPa})\end{array}$ & $\begin{array}{c}\mathrm{YS} \\
(\mathrm{MPa})\end{array}$ & $\begin{array}{l}\text { UTS } \\
(\mathrm{MPa})\end{array}$ & $\mathrm{n}$ & $\begin{array}{c}\mathrm{K} \\
(\mathrm{MPa})\end{array}$ \\
\hline 1. & SS-304 LN & 255.17 & 653.3 & 0.437 & 1452.2 & 258.2 & 665 & 0.441 & 1482.9 \\
\hline 2. & & 256.9 & 663.2 & 0.443 & 1481.2 & 259.1 & 671 & 0.443 & 1498.7 \\
\hline 3. & & 258.54 & 657.7 & 0.428 & 1450.8 & 260.3 & 662 & 0.435 & 1468.9 \\
\hline 1. & $\begin{array}{l}\text { SA-333 } \\
\text { grade- } 6\end{array}$ & 298.9 & 468 & 0.227 & 822.1 & 293.1 & 462 & 0.221 & 804.4 \\
\hline 2. & & 309.0 & 464 & 0.219 & 805.5 & 299.8 & 460 & 0.217 & 796.1 \\
\hline 3. & & 291.2 & 459 & 0.231 & 811.2 & 288.4 & 456 & 0.223 & 796.4 \\
\hline
\end{tabular}


Table 4. Tensile test results for both materials.

\begin{tabular}{lccccc}
\hline Material & \multicolumn{5}{c}{ Tensile test properties } \\
\cline { 2 - 6 } & Type & YS (MPa) & UTS (MPa) & $\mathrm{n}$ & K (MPa) \\
\hline SS-304 LN & Standard & 261 & 644 & 0.467 & 1613.6 \\
SS-304 LN & Miniature & 261 & 636 & - & - \\
SA-333 grade-6 & Standard & 297 & 479 & 0.238 & 828.7 \\
SA-333 grade-6 & Miniature & 309 & 474 & - & - \\
\hline
\end{tabular}

is used for training the network while the command PURELIN is the transfer function used to activate the neurons. Arbitrarily some load-deflection plots are chosen from the database and are input to the trained network for cross checking the network accuracy. In the subsequent step experimental data collection is carried out. After that from the ANN the respective properties for the given input will be obtained.

\section{Results and discussions}

Overall methodology used for the material property evaluation as flow chart format is shown in figure 6. For the different combinations of strain hardening exponent, strength coefficient and yield strength, stress-strain data was generated, which was used for the input in the FE analysis. After the analysis, load-deflection graphs were plotted for different cases with varying strain hardening exponent, strength coefficient and yield strength. Table 1 shows comparison results for some arbitrarily chosen combination of strength coefficient and yield strength for strain hardening exponent of 0.2 , it gives maximum error up to $2.5 \%$ in strain hardening exponent and $2.17 \%$ in strength coefficient. Table 2 shows results comparison for the arbitrarily chosen combination of strength coefficient and yield strength for strain hardening exponent of 0.4 results into the maximum error up to $4.5 \%$ in strain hardening exponent and $1.17 \%$ in strength coefficient. In these cases simulated data generated the load deflection and that data is used empirical relation for the property evaluation. This is done for the verification of the generated data base. Table 3 shows the comparison of the finite element tool results with the help of artificial neural network tool using experimental data of test coupons with experimental data with empirical available formulation of ABI. Table 4 shows the tensile specimen test results.

\section{Conclusion}

In this work, a combination of nonlinear contact finite element analysis and artificial neural network has been applied to explore the possibility of material property execution with automatic ball indentation. The difference between the simulated values of $\mathrm{K}$ and $\mathrm{n}$ obtained from the FEM analysis and the predicted values from the ANN are within the range of $\sim 3 \%$ to $4 \%$ and is in good agreement. The methodology evolved in this work can be extended to predict material properties for any irradiated nuclear material. Further extensions of the ABI tests and their database analysis will lead to evaluation of yield strength, indentation energy to fracture and structural integrity of aged components. 


\section{Appendix A}

Tensile property evaluation using ball indentation experimental data Haggag (1993) and Tabor (1951).

\section{A.1 Estimation of yield strength}

Yield strength of the material is estimated from a plot of $P / d_{t}^{2} v s . d_{t} / D$, corresponding to the unload cycles. The following equation is fit to the data points:

$$
\mathrm{P} / \mathrm{d}_{\mathrm{t}}^{2}=\mathrm{A}\left(\mathrm{d}_{\mathrm{t}} / \mathrm{D}\right)^{\mathrm{m}-2},
$$

where $\mathrm{m}$ is Meyer's constant.

$$
\text { Yield strength, } \sigma_{\mathrm{y}}=\beta_{\mathrm{m}} \mathrm{A}
$$

$\beta_{\mathrm{m}}$ is a constant for a type of material, irrespective of its condition.

\section{A.2 Estimation of UTS}

Corresponding to each unload cycle, the values of true stress $\sigma_{t}$ and true plastic strain $\varepsilon_{p}$ are estimated from an analysis of the following equations:

$$
\begin{aligned}
& \varepsilon_{\mathrm{p}}=0.2 \frac{d_{p}}{D}, \\
& \sigma_{\mathrm{t}}=4 \mathrm{P} / \pi \mathrm{d}_{\mathrm{p}}^{2} \delta,
\end{aligned}
$$

where

$$
\begin{gathered}
\mathrm{d}_{\mathrm{p}}=\left\{0.5 \mathrm{CD}\left[\mathrm{h}_{\mathrm{p}}^{2}+\left(\mathrm{d}_{\mathrm{p}} / 2\right)^{2}\right] /\left[\mathrm{h}_{\mathrm{p}}^{2}+\left(\mathrm{d}_{\mathrm{p}} / 2\right)^{2}-\mathrm{h}_{\mathrm{p}} \mathrm{D}\right]\right\}^{1 / 3} \\
\mathrm{C}=5.47 \mathrm{P}\left[1 / \mathrm{E}_{1}+1 / \mathrm{E}_{2}\right] \\
\delta= \begin{cases}1.12 & \phi \leq 1 \\
1.12+\tau \ln \phi & 1<\phi \leq 27 \\
\delta_{\max } & \phi<27\end{cases} \\
\phi=\varepsilon_{\mathrm{p}} \mathrm{E}_{2} / 0.43 \sigma_{\mathrm{t}} \\
\delta_{\max }=2.87 \alpha_{\mathrm{m}} \\
\tau=\left(\delta_{\max }-1.12\right) / \ln (27)
\end{gathered}
$$

where

$E_{1}$ is the Young's modulus of ball indenter.

$E_{2}$ is the Young's modulus of testing material.

$\alpha_{\mathrm{m}}$ is a parameter which depends on the strain rate sensitivity of the testing material.

True stress $\sigma_{\mathrm{t}}=\mathrm{K} \varepsilon_{\mathrm{p}}^{\mathrm{n}}$, where, $\mathrm{K}$ is strength coefficient and $\mathrm{n}$ is strain hardening exponent. The estimated value of true yield stress is also considered for fitting the power equation to true stress-true plastic strain data.

$$
\mathrm{UTS}=\mathrm{K}(\mathrm{n} / \mathrm{e})^{\mathrm{n}}
$$




\section{A.3 Regression analysis for finding out UTS and $n$}

The power law relation of true stress with true strain is given by

$$
\ln \left(\sigma_{t}\right)=K+n \ln \left(\varepsilon_{p}\right),
$$

this can be expressed as

$$
\mathrm{Y}=\mathrm{a}+\mathrm{bX}
$$

where

$$
\begin{aligned}
& \mathrm{Y}=\ln \left(\sigma_{t}\right), \\
& \mathrm{a}=\mathrm{K}, \\
& \mathrm{b}=\mathrm{n}, \\
& \mathrm{X}=\ln \left(\varepsilon_{p}\right) .
\end{aligned}
$$

By regression analysis formula we have

$$
\mathrm{K}=\overline{\mathrm{Y}}-\mathrm{b}^{*} \overline{\mathrm{X}}
$$

where, $\overline{\mathrm{X}}=\frac{\sum_{i=1}^{j} \mathrm{X}_{i}}{j} \quad \overline{\mathrm{Y}}=\frac{\sum_{i=1}^{j} \mathrm{Y}_{i}}{j}$,

Hardening coefficient $\mathrm{n}$ is given by

$$
n=\frac{j \sum_{i=1}^{j} \mathrm{X}_{i} \mathrm{Y}_{i}-\sum_{i=1}^{i=j} \mathrm{X}_{i} \sum_{i=1}^{i=j} \mathrm{Y}_{i}}{j(j-1) s^{2}},
$$

where $\mathrm{j}$ is the number of loading and unloading cycles in ABI.

Suffix i denotes particulars loading no. in ABI.

And $s^{2}=\frac{1}{j-1} \sum_{i=1}^{j}\left(\mathrm{X}_{i}-\overline{\mathrm{X}}\right)^{2}$.

The strength coefficient K and strain-hardening coefficient can be used to calculate UTS,

$$
\mathrm{UTS}=\mathrm{K}(\mathrm{n} / \mathrm{e})^{\mathrm{n}} .
$$

\section{A.4 Evaluation of parameter A}

Recalling the relation used in yield stress calculation and taking logarithm of both side of above equation,

$$
\ln \left(\mathrm{P} / \mathrm{d}_{\mathrm{t}}^{2}\right)=\ln \mathrm{A}+(\mathrm{m}-2)^{*} \ln \left(\mathrm{d}_{\mathrm{t}} / \mathrm{D}\right) .
$$

The above equation is of the form

$$
\mathrm{Y}=\mathrm{mX}+\mathrm{C}
$$

where

$$
\begin{aligned}
& \mathrm{Y}=\ln \left(\mathrm{P} / \mathrm{d}_{\mathrm{t}}^{2}\right) \\
& \mathrm{X}=\ln \left(\mathrm{d}_{\mathrm{t}} / \mathrm{D}\right)
\end{aligned}
$$


To find out values of parameter A, the following relationship is used

$$
\ln (A)=\overline{\mathrm{Y}}-b \overline{\mathrm{X}}
$$

or

$$
\mathrm{A}=e^{\overline{\mathrm{Y}}-b \overline{\mathrm{X}}}
$$

where

$$
\begin{aligned}
& \overline{\mathrm{X}}=\frac{\mathrm{X}_{1}+\mathrm{X}_{2}+\mathrm{X}_{3}+---+\mathrm{X}_{n}}{n}, \\
& \overline{\mathrm{Y}}=\frac{\mathrm{Y}_{1}+\mathrm{Y}_{2}+\mathrm{Y}_{3}+---+\mathrm{Y}_{n}}{n} .
\end{aligned}
$$

\section{References}

Byan T S, Kim J W, Hong J H 1998 A theoretical model for determination of fracture toughness of reactor pressure vessel steels in the transition region from automated ball Indentation test. J. Nuclear Materials, 252: $187-194$

Haggag F M 1993 In-situ measurements of mechanical properties using novel automated ball indentation system. American Society for Testing and Materials, Philadelphia 27-44

Haggag F M, Nanstad R K 1989 Estimation fracture toughness using tension or ball indentation tests and a modified critical strain model. ASME Pressure Vessel and Piping Conference, 170: 41-46

Lee Y H, Ji W J, Kwon D 2004 Stress measurement of SS400 steel beam using the continuous indentation technique. Experimental Mechanics, 44: 55-61

Mathew M D, Murthy K L, Lietzan L M, Shah V N 1999 Low temperature aging embitterment of CF-8 stainless steel. Material Science and Engineering A269: 186-196

Meyer E 1908 VDI Zeitschrift, 645: 740-835

Murthy K L, Mirgania P Q, Mathew M D 1999 Characterization of gradients in mechanical properties of SA-533B steel welds using ball indentation. Int. J. Pressure Vessel and Piping, 76: 361-369

Tabor D 1951 The Hardness of Metals. Oxford Univ. Press 